\title{
ERP System Implementation: Planning, Management, and Administrative Issues
}

\section{Farhan Mahar, Syed Imran Ali, Awais Khan Jumani* and Muhammad Owais Khan}

Department of Computer Science, ILMA University, Karachi, Pakistan

Article Type: Article

Article Citation: Farhan, Syed Imran Ali, Awais Khan Jumani, Muhammad Owais Khan. ERP system implementation: planning, management, and administrative issues. Indian Journal of Science and Technology. 2020; 13 (01), 1-22. D0l: 10.17485/ijst/2020/v013i01/ 148982

Received date: JNovember 19, 2019

Accepted date: December 3, 2019

*Author for correspondence:

Awais Khan Jumani V awaisjumani@ yahoo.com $९$ Department of Computer Science, LMAA University, Karachi, Pakistan

\begin{abstract}
Motivation: In the modern computing and business world computerization, automation and Enterprise Resource Planning (ERP) system has become the backbone in both public and private sector organizations throughout the world. IT departments in organizations are playing major role in controlling the financial activities, procedures, business, and administrative operations. Problem: In this study, we have analyzed and examined the major issues which an organization could face while starting the ERP project. Objectives: This study will also discuss the significant elements which are crucial for an organization when they move towards the ERP system. Adopting the ERP system for an organization is not only a highly difficult task, but is also an expensive process. Therefore, the organization cannot afford the failure of this implementation plan. Solutions: Moreover, this study is also about the solutions regarding management and administrative plans as well as it helps to design comprehensive controls and procedures for the ERP system implementation project. The issues in the structure, functions, culture, human resource, and procedures of organizations are focused on the study and discussion is made to find out the solutions to control these issues during the implementation process. The study covers the issues regarding implementation plans, project management, and selection or designing of these systems and determines the role of different teams and workforce during the implementation process and after carrying out the process in the business environment.
\end{abstract}

Keywords: Enterprise Resource Planning, Success Factors, Administrative \& Management Issues and Challenges, CSF (Critical Success Factors), CFF (Critical Failure Factors). 


\section{Introduction}

The term Enterprise Resource Planning (ERP) was initially used in the early 1990s. Gartner Group designed an integrated software package to control and enhance the capabilities of their organization and named it as the Manufactured Requirement Planning (MRP), and after the success of the first version they then designed the Manufactured Requirement Planning II (MRP II). After the success of these two versions of MRP, different ERP systems were launched by different organizations and as a result their growth increased in the decade 1990s.

In today's modern computing world, ERP systems are playing major role in managing operations of the organization in both public \& private sectors. These systems are integrated software solutions which are designed to integrate all the information and resources of an organization (shown in Figure 1).

These ERP systems are designed to provide facilities like confidentiality, integrity, and accessibility of the information and resources of an organization, and with the help of these features organizations are improving in their performance, efficiency and as well as in productivity. Moreover, ERP systems can also be described as integrated suite which manages complete operations and procedures of an organization.

ERP systems are adopted in the organizations to integrate all the necessary information so the organization can perform their operations and business procedures more effectively and efficiently. On the other hand, it also improves the performance of an organization.[1]

ERP systems enhance and improve the handling of accounting and management circles. They are helpful in decision making in both public \& private sector organizations. Furthermore, they are helping the organizations to improve their performance with a massive number of solutions for the problems.

Organizations adopt the ERP system for maintaining daily operations, procedures and other functions, so the activities could be done more effectively and proficiently. In addition,

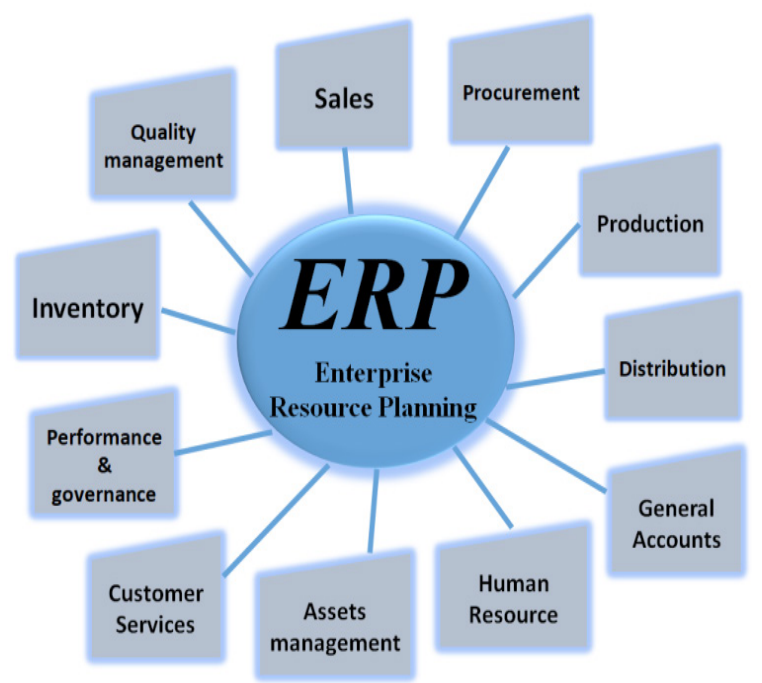

FIGURE 1. ERP system integrity. 
it also manages communication, information, and other services of the organization. ERP system provides innovative ways to the processes and flow the necessary and crucial information between different departments as well as between the workforce.[2]

ERP systems manage, maintain, operate and administrate with highly integrated, synchronized, centralized data and other business processes of the organization. These systems are usually regarded as an essential tool for organizations. Besides, they can achieve their goals successfully with the emerging hands of global markets.[3]

At the present time, computing organizations are more and more moving towards the ERP systems so they can resolve their technical, management, and administrative issues more effectively. Consequently, these systems are also creating sustainable competitive advantages. Due to the functionality of the integrated information, increased number of solutions and strategies for administration, the demand of the ERP systems is rising drastically in current business.

Currently, the most popular manufactures and competitors for ERP systems are as follows:

- SAP

- Oracle Financial by oracle corporation

- People soft Enterprise by Parity Corporation

- PBS manufacturing Series by Passport Soft

- Sales force

- Microsoft

- Net Suite

- Exact Max

- Epicor

- Supper office

ERP system manufacturers, like SAP, Oracle, Net Suite, Microsoft, Epicoretc, are providing software applications and solutions to IT market that support the seamless integration of business activities of an organization.

The market share of these ERP system manufactures and vendors is shown in Figure 2 (Source: Gartner's annual market share reports).[4]

Globally, in ERP system, SAP appeared as a prime leader and now it has become one of the most running ERP system. The main purpose of the SAP is to enhance and re-engineer business procedures. Several organizations in the business world adopted SAP to improve their integrity and performance. Some other competitors in ERP system, includes Oracle Financial by Oracle Corporation, People Soft Enterprise by Parity Corporation, and PBS manufacturing Series by Passport Soft.

ERP system has organized numerous cores of organization operations and procedures. Incorporates them into a comprehensive information model. The system requires data entry once, so the management of information and resources become fast, more accurate, efficient, and productive.

Implementing ERP systems in organization has never been an easy task. It is considered as one of the most difficult responsibility for the management of an organization. Deployment of ERP system requires sufficient management, which includes changes 


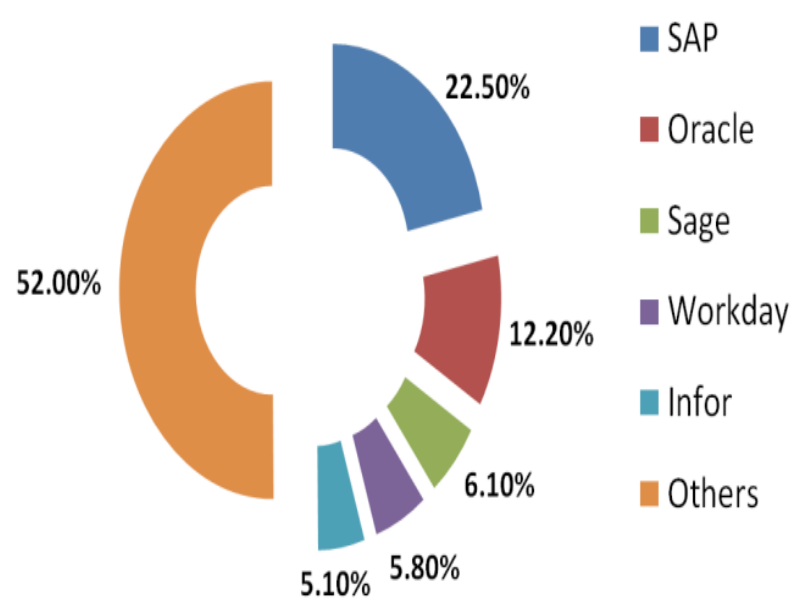

FIGURE 2. ERP vendors share in market.

in the different cores sectors like infrastructure, management, workforce, culture of the organization, etc.

Implementation phase ofERP system consists of four major phases whichare development, testing, deployment, and support. To complete the ERP system implementation project successfully, organization must have generated separate team of experts for each of the said phase. Therefore, the top management requires a comprehensive knowledge to get the fruitful results of ERP system implementation project after its successful completion. [5]

ERP software which is available in the market demands a heavy budget as well as the ratio of the failure of ERP deployment is high. Thus, selecting the ERP system has become a significant part. This part effects all other phases during the implementation process and it also has a great impact on the services after the implementation.

\section{Objective of Study}

The study on the ERP system implementation helps to design the standards and procedures for successful deployment in any organization. The study also covers the hurdles encountered by any organization in the period of the implementation and also have discussed the possible solutions for these issues and challenges. The results and findings of the study provide comprehensive knowledge and information to the organization and assist them to understand the task requirement to achieve the goals accurately and efficiently.

The study on the ERP system's implementation is designed to discover the major factors which are necessary and helpful for the implementation process for an organization. In addition, the study covers the factors which lead to the failure faced by the management during the deployment of project and in the administration of the newly deployed system.

Selection of ERP software for an organization is a significant consequential stage which affects all other aspects of implementation. To select the ERP system, find the ways in 
which management has to focus on the compatibility of system which is chosen for the organizations. It is also important that the selected ERP system will fulfill all operational needs. Then prepare the guidelines for the organization for the selection of efficient consultants, team of champions and experts for the ERP implementation. The selection will help further administration after going-live.

As we know that there is no thumb rule for the implementation process, so it is essential for the organizations to create some golden rules for implementation by analyzing their operation, structure, culture, management, and standard.

Preparing the team of management and IT experts who have the abilities to meet the challenges for the deployment stage.

Find suitable, convenient and challenging environment for the administration, management and IT expert's teams in which they show great concern about the problems and challenges faced during the implementation process and use their comprehensive knowledge and expertise to resolve the issues and problems.

Preparing rules, procedures, policies, strategies, and standards to maintain the integrity, confidentiality, efficiency, accessibility, and standardization, also plan comprehensive training for the workforce and find out the techniques to give them convenient and userfriendly environment.

Emphasis of top management to set standard and procedures to avoid the information gap between organization system and reality created by the users and other stockholders after completion of the project.

Find out the techniques and methods which are followed by the organization after deployment of the system for the careful handling of the system, administration and time to time upgradation.

Study on the ERP System's Implementation is focused on finding the technical aspects, management elements, human resource issues, and some other elements which have become a major source of success or failure. Another objective of this study is to discuss the strategies, structural changes, cultural changes, procedures, human aspects, and role of the different teams of experts in the deployment of an ERP System, it also describes determinations which are used to produce positive results by providing motivation and job commitment to workforce.

The study describes the major success factors which are critical for an organization to create a convenient and challenging environment and make conditions suitable for implementation of ERP systems.

\section{Conceptual Framework}

\subsection{Statement of the Problem}

- The selection or designing of ERP system is an exclusive problem due to the structural and procedural difference between the organizations.

- Difficult to find out the expert consultants or champions of the field for designing and implementation plan of ERP system in an organization. 
- The difference in structure, functions, culture, management, human resource, and procedures among the organization makes it difficult to create a thumb rule for designing and completion of the project in a successful manner.

- Due to the great integration in ERP systems they have great complexity, as a result, these systems create difficulties for the management and IT teams during the designing and implementation process.

- Sometime ERP systems create terrible situations for administration and management; even they might have extensive knowledge regarding these systems as well as their own organization.

- In ERP systems, integration and standardization are the key features, and they limit flexibility in the system of an organization. When the organization losses the flexibility, this situation lead the workforce to produce work-around so the employees of the organization try to move on their previous activities. These types of consequences from the workforce for the implemented ERP system eventually increase workload on the administration, management and also on them.

- Losing the flexibility of the previous system, the response from the staff of the implemented ERP system produce information gaps between the organization system and reality.

- These types of hurdles not only make ERP systems difficult to be implemented for the first time, but they also need great expertise to handle them in an organization.

- ERP software that is available in the market claims a heavy investment and the ratio for non-successful ERP deployment is relatively high, therefore, the selection of the software plays a vital role. This part not only affects the budget of the project, but also effects all other phases of the project during the implementation process. Moreover, it has a great impact on the services after execution of the plan.

- Traditional hierarchy of management, team selection, promotion criteria, and performance-based awards also plays an important role in the downfall of the project.

\section{Scope and Limitation}

The research paper on ERP system implementation is prepared into seven major sections. Section 1 introduces the brief history and functionalities of the ERP system. It provides the information regarding the different ERP software and their vendors. Furthermore, in section 1, the issues and challenges of the ERP system implementation and the objective of the research are also discussed in detail.

Section 2 of the paper contains the previous work examination which was performed by the researchers in the past. The section 3 presents the methods, tools, and techniques which are used to perform the study to find out the issues, challenges, CSF, and CFF for ERP system implementation process. Sections 4 and 5 of the research involves in presenting the findings and results after analyzing of the previous work and survey conducted for the study.

In section 6 of the study a model present for setting up the implementation plan of the ERP system. Moreover, section 7 of the study contains the concluding views and opinion for the study. 


\section{Significance of the Study}

The organizations who are preparing to design an ERP system for their governing procedures or they have selected an ERP system from the software market for implementation has to focus on the selection of proper ERP suite. Moreover, top management commitment, project management, training of the staff, IT infrastructure, hiring of the expert consultant, and creating an open and honest communication between all the stockholders plays a significant role.[6]

The organizations that are going to adopt the ERP systems must have to compare first their procedures, operations, culture, environment and other rules of business first with the ERP system which they have selected or designed for their organization. It is also stated that the poor consultancy and resistance from the high level management is the major factor that increases the ratio of the failure ratio during the implementation phases. [7]

It is proven that the consultant hired from the organizations for carrying out the ERP system has a crucial role during the implementation and ongoing-live phases. It is also discovered that the attention from the top management and experts are significant elements in succeeding of the project

\subsection{Review of Related Literature}

In Ref. [8], the ERP system has become a useful tool for the organizations by making enhancement in their performance. These systems are designed to incorporate all operations of an organization and also to create a competitive relation between all stakeholders of an organization. Furthermore, these systems are also helping to the organizations in re-engineer their operations, procedures and all the other activities it is describing that human resource performs a vital role in the successful implementation of an ERP system in an organization. The ERP systems have great complexity and integrity so they create difficulties for the participants of the organization; therefore, training of the users plays major part for the successful deployment of the system as well as administration after going live.

If an organization adopts ERP system, it is a challenge for all the stakeholders of the organization. Moving towards the ERP system is a decision which is not only expensive but it also consist challenges, issues and hurdles. The core challenge which is face by any organization when they are moving toward the ERP system is the selection or designing of system. This element imposes great influence on all the operations, procedures, and activities of an organization during the implementation process as well as after the implementation in the administration and maintenance process.

In Ref. [9], the organizations which are moving to ERP system has to face several problems in the area of management, planning, development, infrastructure, trainings, stabilizations, and quality assurance. It is also difficult for organization to find expert consultants in order to move towards the ERP system. So they have to focus on creating the team of experts e.g. project managers, project teams, development teams, expert consultants, champions in the organization. 
In Ref. [10], before moving towards the ERPs it is necessary for an organization that to analyzed the system carefully which they will adopt for their operations and compare the system's configuration, procedure, control, flexibility, modification ability, and perform multiple test to ensure that the system which they are adopting must be perfect and compatible with the procedures, operations, culture, environment and other activities of the organization.

In Ref. [11], existing modern computing and business world designing and implementation of the ERP systems have always been a difficult task to control the rest of the organization. The organizations have to show promising approach in moving towards these systems and the administration has to show enormous commitment regarding success of the project. Careful planning is a crucial element. It requires great attention of the planning team to produce comprehensive plans and give the effective changes in the plan when and where required, so the implementation phase to be completed successfully.

In Ref. [12], planning plays an important part during the deployment of ERP system. When the organization is starting the project, the earliest phase for the implementation of ERP system is the planning. However, the inefficient and poor planning for the ERP implementation not only affects all the phases of the implementation but it also increases cost for the project and the time which the organization expects for going live with the system.

In Ref. [13], it was pointed out that availability of sufficient infrastructure; customization and consulting with the clients are the factors which play major role in the deployment of the ERP system in organizations. High level administration and management also focuses on the redesigning of the jobs, trainings, troubleshooting, data integrity, financial and budgetary plan, and selection of consultant and the relations between consultant and organization. Moreover, the organization also has to form a team for management of crises, disaster and recovery.

It was explained that successful completion of the project for deployment of an ERP System is the most important and complex challenge for the organization and it also has a surprisingly high ratio of failure. These systems are highly expensive and they have great effects on the budget of an organization, so it is not affordable to face the situation of failure during the implementation process or after the implementation at administration and management levels. The commitment of the top management of an organization regarding to the ERP implementation has a key role in entire process. Frequent changes in plan and also in the schedules according to challenges and issues help the organization and management to solve them easily and also prepare them for future challenges and issues it is explaining that ERP system has become backbone for the organizations in current industrial environment. The deployment of an ERP has never been a trouble-free mission for the organizations. There are several challenges like selection of the system, finding of expert consultant, preparing of project team etc. which are faced by the organizations when they are moving to the ERP system. The most common issues which are faced by the organizations are the participation and lack of interest from the staff after the conversion of the system which they are using previously into the ERP system. The poor participation of the workforce creates information gaps between system and reality; it creates difficulties for the top management and affects the integrity and efficiency of the system. 
In Ref. [14], it is pointed out that the organizations which are adopting the ERP system definitely face issues about planning, budgeting and in management. The organizations that have strategies to take on the future trends rapidly decrease the chance of failure of ERP system and also remain successful in implementation and management of complete modules of an ERP system. The organizations who show their serious concern about the pitfalls, efficiently address and firmly recognize the issues regarding planning, budgeting, and management always get fruitful results not only in implementations of the system but also achieve significant enhancements in the areas of management and administration.

In Ref. [15], the problems regarding ERP's Implementation are categorized as in advanced countries and in developing countries issues and challenges. They further categories them into environmental factors and internal factors e.g. economy, infrastructure, IT maturity, computer culture, management commitment regulations of the state, etc. The study also shows that developed countries like USA, Canada, UK, Germany, France, Japan, etc. have captured the larger market of ERP because they have a tremendous infrastructure for business and IT society. The government of the developed countries are effectively designing the policies and strategies regarding the IT and business related to IT. Therefore, the organizations of these countries are becoming capable to adopt new technologies and trends rapidly. However, in the developing countries like Pakistan, India, and Brazil (which are selected by the researcher to study) the insufficient infrastructure, inadequate policies from the state, lack of IT experience, and ineffective IT maturity plays a major role in the downfall of an ERP system deployment project.

In Ref. [16], the most widely cited CSF for ERP implementation project are promising commitment and support from the management, vision and planning. Furthermore, promising commitment and support from administration of the organization can be described as a committed leadership of an organization who shows their serious concern about the targets to accomplish the implementation plan successfully. The concept vision \& planning are referred to identifying the perfect objectives and goals for the organization regarding the implementation plan and looking forward toward the success and timely completion by providing clear and perfect objectives and goals. Some other elements which requires the keen attention of the management for successful completion of an ERP project are, balanced team, managing cultural changes, change in management plan, project champions, empowering the decisions makers, communication plans, motivation for the workforce, budget management, client consultation, etc.

In Ref. [17], since ERP systems are introduced in the computing markets (in early 1990s) around the world they are becoming complex and expensive solutions for the businesses. There are several initiatives are taken by the professional communities and academic institutions to overcome these issues. Furthermore, both of these communities innovated a range of solutions which could meet the challenges faced during ERP implementation project and also for managing them effectively. Moreover, they have analyzed all the processes during the implementation since early 1990s and suggested that organizations must involve the end users during the project, generate a multidisciplinary team, design a simple and effective communication plan, choose the team of officers and officials who have significant knowledge and skills in the organization. 
In Ref. [18], "Introducing the ERP system in an organization brings changes on how users work in the organization". Significantly, the area which has a major impact on the ERP system is human resource. The contribution of the users of the organization has an important role for successful deployment of the ERP system. It is found while examining and analyzing that end user's participation of the organization enhances the functionality of multiple modules of system.

In Ref. [19], it is pointed out that adopting ERP is an alarming challenge due to the complex and complicated nature of these software solutions and also due to the high level of budget involvement. They have categorized characteristics of deployment plan into three different phases i.e. planning efforts, decision makings, and empowering the management for the implementation of the system. They have also described that organizations are very sensitive regarding success of the project because there is heavy investment involved for ERP project, and also show serious concerns about the schedule and budget during the rest of the project. In this regard strategies and decisions, significant control on the schedules and completing the project under the appraisal are the sensitive factors for the organizations to complete the implementation plan.

In Ref. [20], it is explained that successful completion of ERP deployment provides great advantages to any organization. It improves and enchases multiple fields and operations. A successful completion of an ERP project helps the organization to achieve their goal significantly and also helps the management in finding, analyzing and resolving their current and future issues and challenges effectively, efficiently and timely. Besides, it is also emphasized that there is an acute need to design a comprehensive model of CSF from project management and other deployment teams to accomplish the tasks and goals regarding the implementation plan. The model should be designed on the basis of the experience of those organizations that have implemented the ERP systems in their environment successfully. The model should also be designed by following the views, comment and feedback from the management, project teams and other stakeholders of these organizations in respond to the effects of system during deployment and administration.

In Ref. [21], most of the organization that are moving towards the ERP systems gives their maximum attention on the culture of the organization and to the top management who is involved in the plan to adopt the system. The study from these researcher shows us that many of the organizations face cultural changes when they are carrying out the process of implementation of these system, the organizations lose the flexibility in their environment so this create hurdles for the employees of the organizations to adopt the system easily. ERP system creates an environment in the organization which is complex in nature and highly integrated. Therefore, the organization has to build a flexible environment for the employees that may consist of centralized sharing of information and resources.

In the view of their research, it is significant that high level management or leadership of the organization who is planning to adopt the ERP system must have enormous influence on the surroundings and the traditions of the organization.

In Ref. [22], case study highlighted that an excellent infrastructure of the IT with a team of IT experts in an organization is the backbone for ERP implementation plan. Any organization who is planning to implement the ERP system has to focus first on the IT 
infrastructure and resources which are available in the organization, examine these factors that whether they are sufficient for the system that is chosen for the organization or not.

In Ref. [23], adopting an ERP system in an organization is a multifaceted and expensive solution in today's world. The complex and highly integrated nature of this system involves different kind of risks during the deployment process. Organizations that are choosing the ERP system for their business have to recognize the risk factors which they could face during the implementation process as well as after the implementation in the management and administration of these systems. Organization must describe that what kind of major risk is associated with the plan of ERP implementation and prepare strategy or tactical steps to encounter those problems when they rise. The organization has to develop a team for the management of risk and should delegate them to design a model to instantly deal with the risk factors.

In Ref. [24], it is pointed out by the researchers that the organizations who are seeking for the adoption of ERP system first have to create a framework which can assess the risk factors. They must have formed a committee or developed a team which is capable to describe, calculate, and analyze the actual outcomes. Furthermore, there must be a framework designed for examining the complete system and the environment of the organization which is functioning under the ERP system so that the risk factors for the ERP system may be reduced. However, if any risk arises, the administration will mitigate, limit and remove it effectively and efficiently.

\section{Methodology}

The main purpose of the study is to find out the issues and challenges encountered by an organization such as planning, managing, and administrating the process of ERP implementation. Methods used for the research is qualitative research approach. It assists in finding out the issues in planning, management, and administration regarding deployment of ERP system in an organization. In addition, to gather more comprehensive and reliable data there are several individual meetings and interviews were organized with the IT professionals, ERP consultants, end users, and other stakeholders. A survey was done by different professionals and the top management of different organization's IT department to get more productive results. These research approaches provide descriptive information to find out the ideas or solutions for the problems regarding subject study. The process of statistical or numerical data collection performed through the survey and interview is mentioned above. The research to find out the issues for planning, management, and administration regarding ERP implementation involves primary and secondary data. The data gathered for examination is collected through the sources like research journals, books, online sources, personal interviews and survey with the professionals of organizations who have best practices regarding the process of ERP implementation.

To find out major challenges and issues for planning, managing, and administrating of the ERP implementation process there are total 65 numbers of papers were selected for literature review and after thoroughly analyzing and examining them in detail a total number of 30 papers were finalized for the research. These papers are extensively involved 
in the research for these issues and challenges. They also clearly \& comprehensively highlight the CSF and CFF in their study.

The process of collecting data for the literature review was implicated after a comprehensive examination of different famous journals. A number of professional members were selected from different organizations who have adopted the ERP systems. ERP consultant, ERP system's implementation teams, IT professionals and end users are also taken on board for the interviews and survey for the subject study. The Model use of the research to find out the issues, challenges, CSF and CFF regarding planning, management, and administration for ERP Implementation Process shown in Figure 3.

\section{Results and Discussion}

Study on the ERP System Implementation is focused to find out the CSF, CFF, technical aspects, management elements, human resource issues, and some other elements which have become major source of success or failure. The major factor which recognized
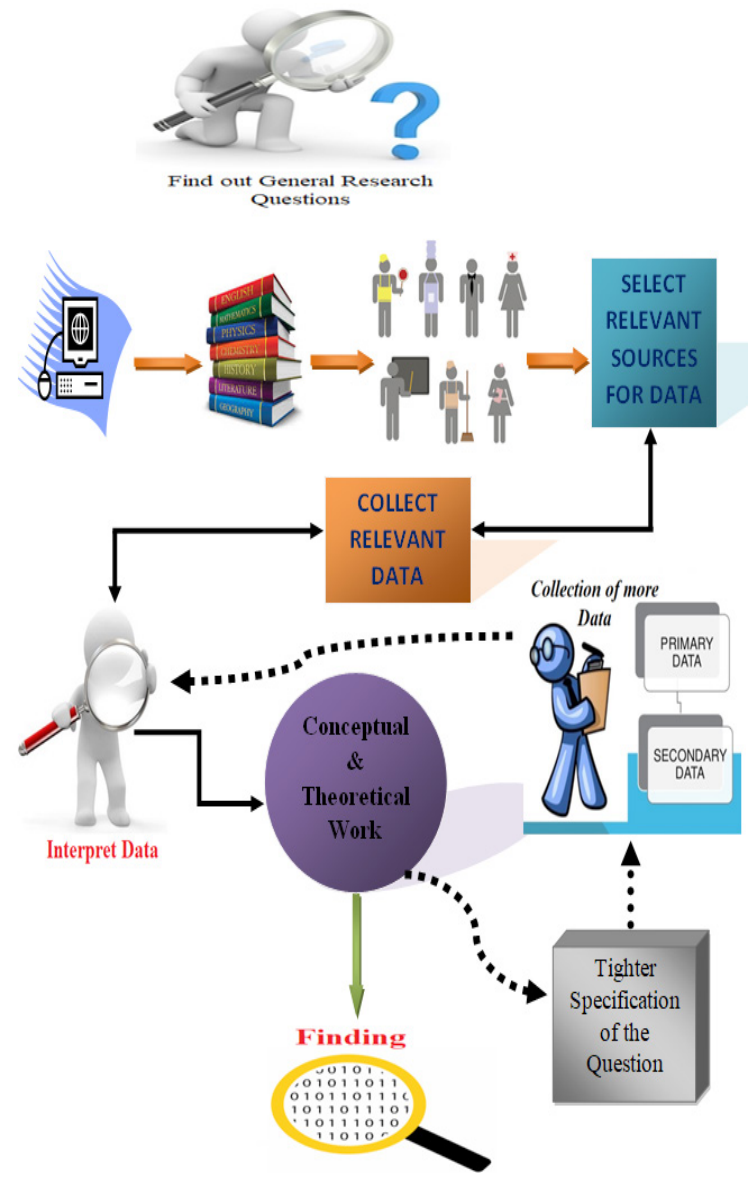

FIGURE 3. Model of research on ERP system. 
as a crucial element for success in implementing ERP system is selection process. Furthermore, organizations that are moving towards the ERP system have to give significance to selection process of ERP system, because selected ERP system must meet the requirements, operations, culture, and other business processes of the organization. Planning phase plays a major role in the success of the ERP systems implementation. ERP systems have great complexity, integrity, large resource commitment, and confidentiality issues, so ERP implementation projects have become a sensitive and intricate exercise during the planning and project management phase. Different ERP system's consultants and analysts always show great concern and promising commitment towards the planning phase. Moreover, promising commitment from the top management is also a vital element for successful completion of implementation plan.

The study shows that the consultant for execution of implementation process plays a major role in the success and organizations have to select expert, efficient and active consultants for the process. Organizations who are adopting the ERP's make significant investments and want comprehensive tools and techniques so the workforce of the organization can utilize newly implemented technology in order to enhancement in the performance of organization. In order to utilize the maximum resources and improve the performance, the organization has to create an efficient, energetic, and enthusiastic team for management of not only implementation process but also for the administration of these systems after completion of implementation process and going live in environment [25].

Implementing an ERP in organization requires a huge investment, so the top management has to plan strategies to control the budgets and also schedule so the implementation process complete in time and not with the acceded budget or extra cost. It is found that the organizations who are adopting the ERP system has to create userfriendly and challenging environment for the project teams and also design convenient and efficient rules, procedures and strategies for these team so they can work in a convenient, friendly and challenging environment for the success of the project with their complete skill and efforts.

\subsection{ERP Software Selection or Designing}

Selection of the ERPs is a difficult problem. It requires to adopting many contradictory criteria and performs several different tests which help to finalize the selection of an ERP system. The most vital and significant phase for implementing an ERP is selection of the software which is available in the IT market or the custom designing process of the software modules for ERP system. Top management, designing, and development teams have to focus on this critical aspect. Organizations have to ensure that the software which they are selecting for their organization not only fulfill all the requirement for running complete business procedures of the organization effectively, comprehensively, efficiently but also it is not within the budget of the organization [26].

All the above mentioned requirements made the selection of ERP process so much valuable and important factor. The selection of ERP not only effect all other phases 
during the implementation process but it also has a great impact on the services after the completion of the project.

\subsection{Selection or Designing of ERP System is an Exclusive Problem Due to the Structural and Procedural Difference Between the Organizations}

Different organizations have several different kinds of businesses and procedures. Sometimes they have great variation in structure, functions, culture, management, human resource, and procedures. These difference and variations create trouble for the management, development, and designing teams in the selection of the ERP system [27]. To deal with this problem, the organization needs to emphasize on re-structuring their business processes, operation, and procedures. They also need to adopt a customize approach to change their structure, culture, management and other functioning areas rapidly when and where required.

\subsection{Selection of the Team}

Development of the team for the ERP implementation project can be different from organization to organization. Generally the project for the deployment of ERPs begins with complete support of the administration and higher level management. However, Selection of top management is a crucial element because the initiatives taken by this team to establish several different strategies for development plays an important part in the successful completion of project.

Selecting team for the implementation of ERP in any organization plays a major role. It may results in the shape of success or might be a cause for the failure of complete project. The implementation process of ERP consists of four major phases which are development, testing, deployment, and support. To avoid the failure and for a successful implementation, the organization has to create separate team of experts for each of the above mention phases. It has been analyzed that the traditional team selection criteria, promoting the old staff as core team members for the ERP implementation and appointing the staff on senior and critical posts on favoritism also become as CFF after the organization going live with the ERP systems. These conditions creates garbage-in garbage-out situation regarding the human resource of organization and after some time it results in the project's fall down or become a nightmare for the organization.

\subsection{Finding the Expert Consultants or Champions}

Finding the expert consultants and champions of the field for ERP has a great impact throughout the project for implementing the ERP system, because they have comprehensive expertise and knowledge to meet the challenges and problems related to the deployment and management of the ERP system [28]. To achieve success in implementing the ERP system, there should be only one expert or champion of the field may be selected. This expert or champion of the field led the implementation team. Moreover, he should be a 
member of top management of the organization, so he will provide an appropriate support during the implementation project.

Any organization that is moving towards the ERP system has to gather a team of proficient of the field (e.g. Expert Consultant Project Champion, Highly capable implementing Team, trained IT Staff, Superior outside Advisory Support, large Vendor Partnership, etc.). Organization must find and prepare a highly capable team of management and IT experts which show great commitment to meet the challenges during the implementation process of ERPs. This team is required to build an effective bridge of communication between all the stakeholders and set Business vision Goals and Objectives.

They are required to perform rapid changes in the management, organization structure and culture for achieving high level of performance and also meet the standards set by management of organization. This team may also be responsible to provide necessary information, training and knowledge to the workforce so they can perform their tasks and duties with great motivation and in a convenient manner.

\subsection{Creation of a Thumb Rule}

It is analyzed during research that due to the variation and differences in structure, function, culture, management, human resource, and procedure, there are so much difficulties faced by the management to create a thumb rule for the implementation process of an ERP system. It is necessary for the organizations to create some golden rules for implementation by analyzing their operation, structure, culture, management, and standards. It is also required that some special standards and procedures should be designed by the top management and by team of experts with consulting all the other stakeholders of the organization. These standards and procedures may not only be followed by the organization for implementation phase but also these standards and procedures may be followed strictly after the completion of project as well as after going live with the ERP system.

\subsection{Great Integrity and Complexity}

The ERP system not only has great integrity but they are complex software solutions and sometimes they generate problems during the designing and implementation process for management and IT team of an organization. The top management and IT teams have to focus all the time on the integrity and complexity and provide solution regarding the problems and issues due to the complexity of the software. The top management, consultant, and other IT experts may show their great concern to maintain integrity of the ERP system. If they do not focus on the integrity of ERP system, it would results in the shape of information gaps and other critical issues.

The organizations must develop a team of efficient, energetic, enthusiastic members who are responsible to deal the complexity issues regarding the ERP system and also maintain integrity between all the operations efficiently and effectively. The team may also be responsible to deal with the information gaps produce by the workforce due to losing of the flexibility of previous system. 


\subsection{Problems for Administration and Management}

ERP system creates terrible situations for administration and management (even they might have comprehensive knowledge of the ERPs). To face these kinds of problem organization must find a suitable, convenient and challenging environment for the administration, management and IT teams in which they show great concern about the problems and challenges faced during the implementation process and use their knowledge and expertise to resolve the issues and problems [29]. Moving towards an ERP system requires a huge investment from the organization so the failure in the implementation is not acceptable. Therefore, the management has to plan strategies to control the budgets and also schedule so the implementation process complete in time and not with the acceded budget or extra cost. The management has to create motivation in the workforce and provide them a userfriendly and challenging environment.

The management has to design flexible, convenient, efficient, challenging rules, procedures and standards so different teams for the implementation process can perform their task in a suitable, friendly and challenging environment and also utilize their complete skills and efforts to enhance the performance of the organization.

\subsection{Problems and Resistance from the Workforce}

The workforce of the organization plays the role of backbone in all the operation. When an organization is adopting an ERP system, it losses the flexibility which is provided in the previous system. The workforce of the organization which is familiar with the flexibility of the previous system tries to move on their previous or manual processes. This kind of situation produces information gaps and some other issues. To deal with this kind of resistance and situation, the organization must have to prepare comprehensive training for the staff and find the tools and techniques to create motivation in the workforce and to give them a convenient and user-friendly environment so they can perform their duties proficiently and effectively in the newly adopted system.

Information and effective communication is the most popular strategic tool in any organization. They provide numerous advantages for the success of an implementation project and also in the management and administration of the ERPs after the deployment [30]. The organizations who are adopting the ERP system have to design the necessary structures for the transfer of knowledge to their workforce regarding the newly adopted system, so they can learn more about their responsibilities in the organization and perform their duties more effectively and efficiently.

\subsection{Information Gaps Between the Organization System and Reality}

Sometime after losing suppleness of previous system, reaction from the workforce for the deployed ERP system produce information gaps between the organization system and reality. This has also resulted as an ineffective and inefficient performance by the workforce who is familiar with the pervious flexible system. To deal with this challenge management 
of the organization has to prepare rules, procedures, policies, strategies and standards to maintain the integrity, confidentiality, efficiency, accessibility and standardization. They have also designed training sessions which are helpful to increase knowledge of the workforce regarding the newly introduced ERP system.

\subsection{Traditional Hierarchies of Management, Team Selection, Promotion Criteria and Performance Awards}

Traditional hierarchy of management, team selection, promotion criteria, and performance award has also become a major factor of failure after going live with the ERP systems. It is observed that making appointments on the critical and top level positions though promoting the old staff on seniority or on favoritism basis plays a major role in the failure of the project. Awards on performance to the workforce by following the traditional hierarchy and inadequate manner also demoralize the workface who play a major role and perform their task in an extraordinary manner for the success of the entire project.

When in an organization, promotion and awards that are given by following the traditional hierarchy and favoritism basis produce a situation which is known as garbage-in garbage-out. This kind of situation demoralizes the workforce who has not only shown their extra ordinary skills for the success of the project, but has performed their tasks with great commitment and dedication. To avoid this situation, the top management has to design criteria in which all the workforce has the equal opportunity to achieve the awards and promotion as per their performance.

After implementing ERP system, organizations must align tasks and goals for the individual and different teams. On the successful achievement of these goals they may be awarded with incentives and promotions. This will motivate the workforce so they will utilize their complete skills for the improvement in the performance of the organization. The promotion criteria must be designed on the performance cum fitness basis (including higher qualification, experience, achievements, and expertise) it will help to resolve the garbage-in and garbage-out element.

\subsection{Survey Findings}

For the research to find out the issues, challenges, CSF and CFF regarding the ERP implementation process, results mentioned in the Table 1 are prepared through the answers from the respondents.

Majority of the respondent for the survey (99\%) acknowledged that the software selection plays a vital role in the success of the implementation plan. In the light of the survey results, we can declare the selection of the software as the most significant CSF for the implementation of the ERP system. In the light of the responses from the population of the survey, the issue of structural and procedural difference among the organizations creates ultimate challenge for the selection or design of the ERP system. Selecting and gathering the team for the implementation plan has also a complex task for the organization. It becomes as a nightmare for the administration when the top management has follow the traditional hierarchies, and selection criteria. Both of these issues acknowledge by the 
TABLE 1. Survey results

\begin{tabular}{|c|c|c|c|}
\hline \multicolumn{4}{|c|}{ Survey findings } \\
\hline Description & Agreed & Disagreed & Neutral \\
\hline ERP Software selection & $99 \%$ & $1 \%$ & \\
\hline $\begin{array}{l}\text { Selection of ERP system is an exclusive } \\
\text { problem due to the structural and } \\
\text { procedural difference between the } \\
\text { organizations }\end{array}$ & $87 \%$ & $3 \%$ & $10 \%$ \\
\hline Selection of the team & $70 \%$ & $8 \%$ & $22 \%$ \\
\hline Finding the expert consultants & $67 \%$ & $12 \%$ & $21 \%$ \\
\hline Creation of a thumb rule & $65 \%$ & $20 \%$ & $15 \%$ \\
\hline Great integrity and complexity & $73 \%$ & $16 \%$ & $11 \%$ \\
\hline $\begin{array}{l}\text { Problems for administration and } \\
\text { management }\end{array}$ & $48 \%$ & $34 \%$ & $18 \%$ \\
\hline $\begin{array}{l}\text { Problems and resistance from the } \\
\text { workforce }\end{array}$ & $60 \%$ & $23 \%$ & $17 \%$ \\
\hline $\begin{array}{l}\text { Information gaps between the } \\
\text { organization system and reality }\end{array}$ & $61 \%$ & $25 \%$ & $14 \%$ \\
\hline $\begin{array}{l}\text { Traditional hierarchies of management, } \\
\text { team selection, promotion criteria and } \\
\text { performance awards }\end{array}$ & $66 \%$ & $25 \%$ & $9 \%$ \\
\hline
\end{tabular}

majority of the survey population (70\%) as CSF or CFF for any implementation plan of ERP system.

Furthermore, analyzing issues, challenges CSF and CFF for planning, management, and administration during ERP implementation process we can further categories critical factors and issues in five categories which are the essential elements of an ERP system implementation project. They are as follows:

- Stakeholders

- Process

- Technology

- Organization

- Project Management

During the study and research, there are some other critical aspects observed that requires the absolute attention of the organizations when they are performing the implementation process of the ERP system implementation in their environment. These include the following:

- Getting upper management support

- Change management

- Setup parameters

- Hardware and software arrangement

- Business flow procedures

- Adjustment and modification facilities

- Internal controls and standard reports 
- System alignment checking with the current business procedures of the organizations

- Gain knowledge about the system's strengths, weaknesses

\subsection{Purposed Model for ERP Implementation Plan}

After brief study and research regarding challenges faced by an organization in relation to the Planning, Management, and Administration during ERP Implementation Process, a model (shown in the Figure 4) is recommending adopting for the deployment of an ERP System in organizations more effectively and efficiently. The model should be supportive for successful completion of ERP system's implementation process as well as it is helpful to find and resolve the issues during the implementation process more effectively and efficiently.

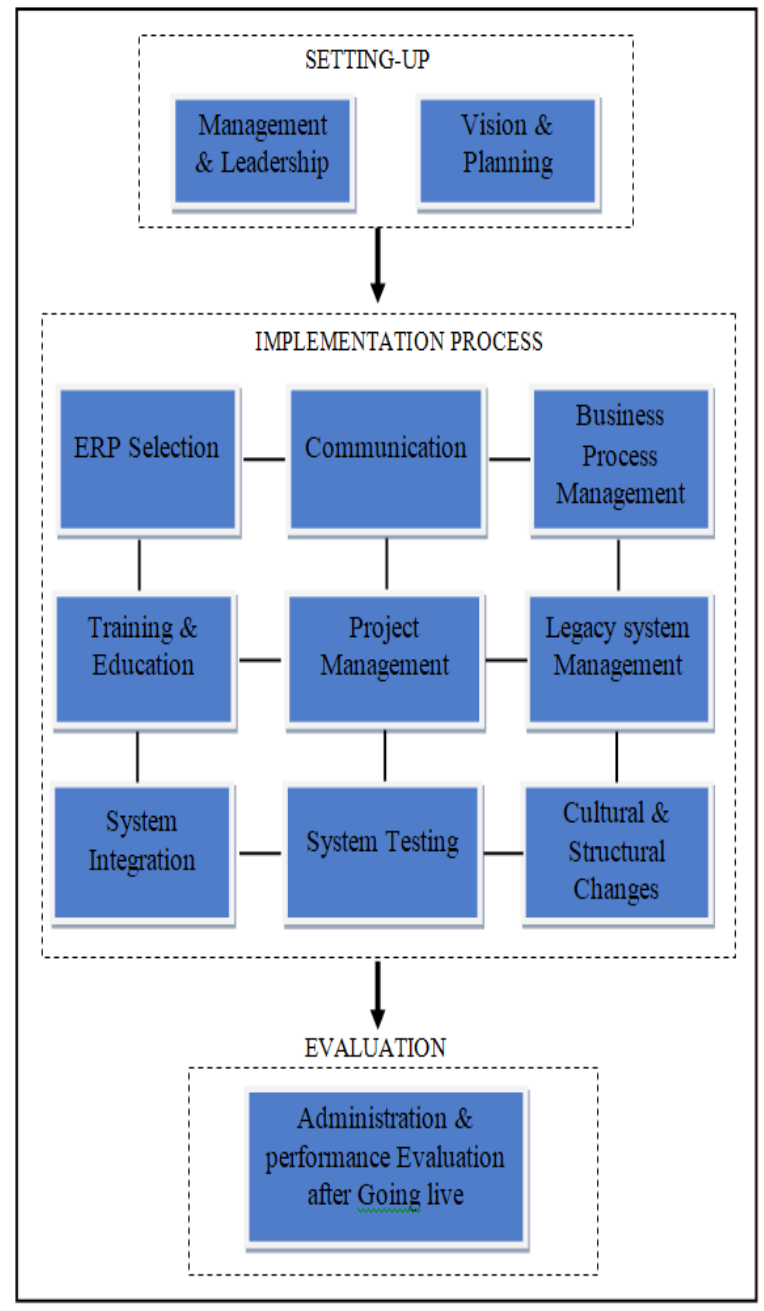

FIGURE 4. Purposed model for ERP implementation plan. 


\section{Conclusion and Recommendation}

Study on the ERP system's Implementation is focused to find out the technical aspects, management elements, human resource issues and some other elements which might become as major source of success or failure. The study is also conducted to discuss the strategies, structural changes, cultural changes, procedures, human aspects, and role of the different teams of experts in the successful completion of an ERP System project in an organization. The study describes the determination which is used to produce positive results by creating motivation and job commitment for the workforce. The organization has to create a convenient and challenging environment for workforce and also to make conditions suitable for deployment of ERPs. The top management has to show great concern about analyzing that the performance and roles of the individuals of the organization do not affect the organizational performance during the implementation process as well as after going live in business environment.

It is found that the planning phase plays a vital role in the ERP system deployment for an organization. It is the earliest phase of a project when an organization is seeking to adopt ERP system. Soon after the planning phase it is necessary to make changes in the management which is essential for the successful completion of the project. Another major factor is selection of the right ERP system which plays major role for the success of the implementation plan. It also has a great impact on other phases of the project as well as after the implementation of the system on the administration and management.

\section{Recommendation}

Organizations have to design different kind of rules, procedures, policies, strategies and standards to maintain the integrity, confidentiality, efficiency, accessibility, and standardization. There is an acute need in organizations to provide comprehensive training to the staff and finding out the techniques to give them convenient and userfriendly environment so they can easily work in the ERP system's environment. The implementation of the ERP system is time consuming and requires extraordinary efforts, multiple teams of experts and champions, huge funds. To achieve success for deployment of ERP in any organization, the management has to recognize and execute best practices during the ERP implementation process.

\section{References}

1. Shen YC, Chen PS, Wang CH. A study of enterprise resource planning (ERP) system performance measurement using the quantitative balanced scorecard approach. Computers in Industry. 2016; 75, 127-139.

2. Zimmerman E, Smedley J. ERP Implementations-a never ending story? IRIS 29, paradigms politics paradoxes, 29th information systems research seminar in Scandinavia, Helsingør, Denmark. 2006, 12.

3. Kilic HS, Zaim S, Delen D. Development of a hybrid methodology for ERP system selection: the case of Turkish airlines. Decision Support Systems. 2014; 66, 82-92. 
4. Market share analysis: ERP software, worldwide. https://www.gartner.com/en/ documents/3879510/market-share-analysis-erp-software-worldwide-2017. Date accessed: 22/06/2019.

5. Sadrzadehrafiei S, Chofreh AG, Hosseini NK, Sulaiman R. The benefits of enterprise resource planning (ERP) system implementation in dry food packaging industry. Procedia Technology. $2013 ; 11,220-226$.

6. Huang Z. A compilation research of ERP implementation critical success factors. Issues in Information Systems. 2010; 11(1), 507-512.

7. Seo G. Challenges in implementing enterprise resource planning (ERP) system in large organizations: similarities and differences between corporate and university environment. Doctoral dissertation. Massachusetts Institute of Technology. 2013.

8. Al-Mashari M, Al-Mudimigh A. ERP implementation: lessons from a case study. Information Technology \& People. 2003; 16(1), 21-33.

9. Kumar V, Maheshwari B, Kumar U. An investigation of critical management issues in ERP implementation: emperical evidence from Canadian organizations. Technovation. 2003; 23(10), 793-807.

10. Puri R. Best practices of ERP implementation. North Dakota State University. 2014, 1-30.

11. Françoise O, Bourgault M, Pellerin R. ERP implementation through critical success factors' management. Business Process Management Journal. 2009; 15(3), 371-394.

12. Mandal P, Gunasekaran A. Issues in implementing ERP: a case study. European Journal of Operational Research. 2003; 146(2), 274-283.

13. Jamil MY, Qayyum MR. Enterprise resource planning (ERP) implementation in Pakistan enterprises: critical success factors and challenges. Journal of Management and Research. 2015; $11(2), 1-17$.

14. Chen IJ. Planning for ERP systems: analysis and future trend. Business Process Management Journal. 2001; 7(5), 374-386.

15. Huang Z, Palvia P. ERP implementation issues in advanced and developing countries. Business Process Management Journal. 2001; 7(3), 276-284.

16. Finney S, Corbett M. ERP implementation: a compilation and analysis of critical success factors. Business Process Management Journal. 2007; 13(3), 329-347.

17. Aladwani AM. Change management strategies for successful ERP implementation. Business Process Management Journal. 2001; 7(3), 266-275.

18. Matende S, Ogao P. Enterprise resource planning (ERP) system implementation: a case for user participation. Procedia Technology. 2013; 9, 518-526.

19. Mabert VA, Soni A, Venkataramanan MA. Enterprise resource planning: Managing the implementation process. European Journal of Operational Research. 2003; 146(2), 302-314.

20. Soja P. Success factors in ERP systems implementations: lessons from practice. Journal of Enterprise Information Management. 2006; 19(4), 418-433.

21. Ke W, Wei KK. Organizational culture and leadership in ERP implementation. Decision Support Systems. 2008; 45(2), 208-218.

22. Light B, Holland CP, Wills K. ERP and best of breed: a comparative analysis. Business Process Management Journal. 2001; 7(3), 216-224.

23. Sumner M. Risk factors in enterprise-wide/ERP projects. Journal of Information Technology. 2000; 15(4), 317-327.

24. Huang SM, Chang IC, Li SH, Lin MT. Assessing risk in ERP projects: identify and prioritize the factors. Industrial Management \& Data Systems. 2004; 104(8), 681-688. 
25. Maas JB, van Fenema PC, Soeters J. ERP system usage: the role of control and empowerment. New Technology, Work and Employment. 2014; 29(1), 88-103.

26. Efe B. An integrated fuzzy multi criteria group decision making approach for ERP system selection. Applied Soft Computing. 2016; 38, 106-117.

27. Ahmed S, Khan MA, Memon ZA. Organizational culture and its impact on employee career progression in public sector organizations in Pakistan. IBT Journal of Business Studies. 2014; 10(2), 1-16.

28. Maditinos D, Chatzoudes D, Tsairidis C. Factors affecting ERP system implementation effectiveness. Journal of Enterprise Information Management. 2001; 25(1), 60-78.

29. Elkhani N, Soltani S, Nazir Ahmad M. The effects of transformational leadership and ERP system self-efficacy on ERP system usage. Journal of Enterprise Information Management. 2014; 27(6), 759-785.

30. Jeng DJF, Dunk N. Knowledge management enablers and knowledge creation in ERP system success. International Journal of Electronic Business Management. 2013; 11(1), 49. 